\title{
Current strategies for the prevention and management of central line-associated bloodstream infections
}

This article was published in the following Dove Press journal:

Infection and Drug Resistance

22 November 2010

Number of times this article has been viewed

\author{
Zhuolin Han \\ Stephen Y Liang \\ Jonas Marschall \\ Division of Infectious Diseases, \\ Washington University School \\ of Medicine in St Louis, St Louis, \\ MO, USA
}

\begin{abstract}
Central venous catheters are an invaluable tool for diagnostic and therapeutic purposes in today's medicine, but their use can be complicated by bloodstream infections (BSIs). While evidence-based preventive measures are disseminated by infection control associations, the optimal management of established central line-associated BSIs has been summarized in infectious diseases guidelines. We prepared an overview of the state-of-the-art of prevention and management of central line-associated BSIs and included topics such as the role of antibioticcoated catheters, the role of catheter removal in the management, and a review of currently used antibiotic compounds and the duration of treatment.
\end{abstract}

Keywords: central venous catheters, bloodstream infections, guidelines, prevention

\section{Introduction}

Central venous catheters (CVCs) are indispensable in medical care today. They are used for monitoring the hemodynamic status, for performing hemodialysis, and for administering medications, fluids, blood products, and total parenteral nutrition. In the United States, more than 150 million intravascular devices are sold each year. ${ }^{1}$ Intravascular devices are available in different types based on their purposes and the anticipated duration of catheterization and can be classified into short-term versus long-term catheters, with the latter requiring surgery for insertion. Although, mostly encountered in intensive-care units (ICUs), CVCs are increasingly used in non-ICU wards $^{2}$ and outpatient settings. However, rates of CVC use are much higher in ICUs than in other settings, and the associated morbidity is greatest in the critically ill patient population.

Owing to the invasive procedure necessary for placing a CVC and the remaining break in the integument, complications such as exit-site infections and bloodstream infections (BSIs) can develop. Pathogens either migrate along the outer surface of the catheter into deeper tissue and the bloodstream, or, less commonly, they are introduced into the catheter hub and proceed along the lumen. CVC-associated BSIs or central lineassociated bloodstream infections (CLABSIs) are among the most frequent health careassociated infections. The infection risk varies with a number of factors, eg, the type of device, ${ }^{3}$ the insertion site, ${ }^{4}$ and the adherence to preventive measures. ${ }^{5}$ In situations of unknown risk factors, root cause analyses have been helpful and are recommended by national associations such as APIC (http://www.apic.org/Content/NavigationMenu/ PracticeGuidance/APICEliminationGuides/CRBSI_Elimination_Guide_logo.pdf). It also appears that the infection risk is not linear along the catheter age but increases
Correspondence: Jonas Marschall Division of Infectious Diseases, Washington University School of Medicine in St Louis, St Louis, MO, USA Email jmarscha@dom.wustl.edu 
over time. It is estimated that 250,000 episodes of CLABSI occur in the United States each year, with an attributable mortality of $12 \%-25 \% .{ }^{6}$ In addition, CLABSIs are known to increase the length of hospital stays as well as hospital costs. Hematogenous complications that may arise from CLABSI include endocarditis and osteomyelitis.

Incidence rates of catheter infections are usually presented as number of infections per 1000 catheter-days. The manual collection of data for this denominator is relatively timeconsuming; therefore, electronic algorithms have been studied with the goal of facilitating surveillance. ${ }^{7}$ Reported rates range from $<1$ BSIs/1000 catheter-days ${ }^{8}$ to $\sim 10$ and more ${ }^{9}$ but have been shown to decrease to 0 after interventions. ${ }^{10}$ The microbial spectrum includes a variety of Gram-positive and Gramnegative bacteria as well as yeasts, with the predominant organisms being Staphylococcus aureus, coagulase-negative Staphylococci (CNS), and Candida species (spp.). Catheter colonization with skin organisms can occur without producing any clinical symptoms.

Physical findings alone do not make for reliable diagnosis of a CLABSI. In the clinical setting, a CLABSI is commonly diagnosed by positive blood culture(s) and the absence of an apparent focus of infection other than the catheter. The CDC surveillance definition of a laboratory-confirmed BSI requires a positive blood culture in a patient where the recovered organism cannot be related to an infection at another site: ${ }^{11}$ if a CVC has been in place at the time of the BSI or within the previous 48 hours, a CLABSI can be diagnosed. Importantly, no minimum of required catheter retention time has been formulated as part of this definition (see http:// www.cdc.gov/nhsn/PDFs/pscManual/4PSC_CLABScurrent.pdf).

Blood cultures should be obtained from both the catheter and peripherally prior to starting antibiotics, and following adequate skin preparation. Growth of $S$. aureus, CNS, and Candida spp. in blood cultures should raise the suspicion of CLABSI. Common skin contaminants are more difficult to interpret. If symptoms improve after removal of a catheter, even without any microbiological diagnosis, this is also suggestive for a CLABSI. For suspected exit-site infections with drainage, an exit-site culture should be obtained.

Diagnostic approaches (along with laboratory criteria for diagnosis) are dependent on the capacity of the individual lab and can be classified based on whether the catheter is removed or retained. They include the semiquantitative method propagated by Maki et al, in which the catheter in question is removed and its tip rolled over an agar plate ('roll-plate method'). ${ }^{12}$ This method requires $>15$ colony-forming units
(CFU) from the catheter tip and the same organism growing from blood cultures; it exhibits high sensitivity and specificity. Another method involves luminal flushing or sonication in order to obtain quantitative data. A cutoff or $1000 \mathrm{CFU}$ has been shown to be indicative of infection, particularly in long-term catheters. However, both of the above methods require removal of the catheter and should only be used if a CLABSI is highly suspected. One of the methods not requiring catheter removal is to draw blood simultaneously through the catheter in question as well as peripherally and to compare colony counts. (CFU are required to be 3-5 times as high in catheter blood cultures than in peripherally obtained blood cultures in order to make a diagnosis of CLABSI). ${ }^{13}$ In the cited meta-analysis by Safdar et al, this method turned out to be the most reliable diagnostic approach. Also, catheter-drawn quantitative cultures can be obtained (with a cutoff of $100 \mathrm{CFU} / \mathrm{mL}$ ) and in contrast, they appear to be the most cost-effective approach. ${ }^{14} \mathrm{~A}$ third approach measures the differential time until blood cultures turn positive; if the catheter blood culture turns positive at least 2 hours before the peripheral blood culture does, this argues in favor of a catheter infection. ${ }^{15}$ Qualitative methods are not recommended. ${ }^{1}$

In this review, we summarize and discuss aspects of prevention and management of CLABSIs. Detailed guidelines on both prevention and management have been published recently and should be consulted for further guidance. ${ }^{1,16}$

\section{Prevention of central line-associated bloodstream infections}

The Society for Healthcare Epidemiology of America (SHEA) and the Infectious Diseases Society of America (IDSA) have recently published guidelines compiling evidence-based approaches to prevent health care-associated infections in acute care hospitals and, more specifically, CLABSI. ${ }^{16,17}$ These updated guidelines serve in concert with pre-existing guidance provided by the Healthcare Infection Control Practices Advisory Committee (HICPAC) as a basis for framing a discussion of current CLABSI prevention strategies. ${ }^{18}$

\section{Prior to catheter insertion}

Education

Education remains the cornerstone of prevention of CLABSI and other nosocomial infections. ${ }^{19}$ In a prospective pre-post observational trial involving medical students and resident physicians, a 1-day instructional course on infection control emphasized the importance of using a full-size sterile drape as part of aseptic technique when placing a CVC. As a result, ${ }^{20}$ 
documented use of full-size drapes increased from $44 \%$ to 65\% $(P<0.001)$, while CLABSI rates decreased from 3.3 to 2.4 infections $/ 1000$ catheter-days. Another educational program consisting of a self-study module, staff in-service lectures, and the placement of fact sheets and posters throughout the intervention unit to reinforce key infection-prevention concepts was directed toward physicians and nurses in a tertiary teaching hospital. CLABSI rates dropped significantly after the program was introduced in the medical ${ }^{21}$ and surgical ICU ${ }^{22}$ of that hospital as well as in the ICU of an affiliated nonteaching community medical center. ${ }^{22,23}$ A subsequent, multicenter observational study further validated this strategy, leading to a reduction in CLABSI rates from 11.2 to 8.9 infections/1000 catheter-days in the ICUs of six academic medical centers (risk ratio [RR] 0.79; 95\% confidence intervals [CI]: 0.67-0.93). ${ }^{24}$ The use of hands-on, simulation-based training in proper CVC insertion as a supplement to didactic lectures also contributes to lowering CLABSI rates. ${ }^{20,25}$ Educational programs should be coupled with a formal credentialing process on an institutional basis to ensure the procedural competency of health care workers charged with placing CVCs. Periodic reassessment of health care worker knowledge regarding infection-prevention practices should be instituted to promote continued adherence to evidence-based practices.

\section{At the time of catheter insertion Hand hygiene}

Hand hygiene remains a key measure in reducing nosocomial infections in the health care setting. ${ }^{26}$ Health care workers' hands are frequently contaminated by organisms acquired from colonized patients and their immediate environment, and these may be readily transmitted to other patients in the absence of adequate hand hygiene. ${ }^{27}$ A relationship between proper hand hygiene and decreased nosocomial infections and cross-transmission has been established in several studies over the last 30 years. ${ }^{28}$ A comprehensive hand hygiene promotion program in Switzerland not only improved compliance but also reduced nosocomial infections from a baseline prevalence of $16.9 \%$ to $9.9 \%(P=0.04)$ in 4 years. ${ }^{29}$ For the most part, the specific impact of improved hand hygiene on CLABSI has been measured as part of comprehensive infection-prevention strategies. In patients receiving parenteral nutrition, hand hygiene reduced CLABSI rates by $72 \%$ (odds ratio [OR] 0.28; 95\% CI: $0.09-0.88$ ). ${ }^{30}$ After institution of an educational and performance feedback program to improve hand hygiene compliance in the ICU, a hospital in Argentina reported a dramatic increase in compliance from
$23 \%$ to $65 \%$ with a concomitant drop in overall nosocomial infection from 48 to 28/1000 patient-days (RR 0.59; 95\% CI: $0.46-0.74 ; P<0.0001) .{ }^{31}$ In a prospective interventional cohort study targeting instruction of proper hand hygiene and catheter care, compliance with hand hygiene improved only slightly from $59 \%$ to $65 \% .{ }^{32}$ However, correct performance of hand hygiene increased from $23 \%$ to $43 \%(P=0.003)$ and CLABSI rates decreased from 3.9 to $1.0 / 1000$ catheterdays after the intervention $(P<0.001)$. Hand hygiene with either an alcohol-based waterless product or antiseptic soap and water is mandated prior to CVC placement regardless of the fact that sterile gloves will be donned during the procedure.

\section{Sterile precautions}

Protective sterile barriers and clothing help minimize the risk of contamination and colonization of the catheter and insertion site during CVC placement. The benefit of maximal sterile barrier precautions (MSBPs), consisting of a surgical gown, sterile gloves, mask, cap, and a large sheet drape, in limiting CLABSI was initially borne out in a single-center randomized, controlled trial involving cancer outpatients receiving chemotherapy.$^{33}$ CLABSI rates were sixfold higher in the control group which used only sterile gloves and a small drape (standard sterile barrier precautions, SSBP) during catheter placement when compared to the intervention group assigned to use MSBP ( 0.5 versus 0.08 infections/ 1000 catheter-days for the control versus the intervention group, respectively; $P=0.02$ ). In a later prospective observational study, proper implementation of MSBP during CVC placement reduced CLABSI rates in patients receiving parenteral nutrition by $74 \%$ (OR $0.26 ; 95 \%$ CI: $0.08-0.93) .{ }^{30}$ Interestingly, a recent, multicenter randomized, controlled trial involving general surgery inpatients in Japan found no significant difference in CLABSI rates between SSBP and MSBP during CVC insertion (RR 0.84; 95\% CI: 0.26-2.7; $P=0.77) .{ }^{34}$ The investigators, however, acknowledged that their study was underpowered to detect significant differences in CLABSI rates reported in the previous literature. MSBPs should be used throughout the entire procedure of CVC placement.

\section{Skin antisepsis}

Skin preparation with an antiseptic decreases the burden of skin flora at the site of catheter insertion. In a randomized, controlled trial comparing $10 \%$ povidone-iodine, $70 \%$ alcohol, and $2 \%$ aqueous chlorhexidine for disinfection of central venous and arterial catheter sites in surgical ICU 
patients at the time of insertion and with subsequent daily catheter site care, chlorhexidine was associated with the lowest incidence of CLABSI. ${ }^{35}$ In 2002, a meta-analysis of eight randomized, controlled trials revealed a summary RR for CLABSI of 0.49 (95\% CI: 0.28-0.88) in patients whose catheter sites were disinfected with chlorhexidine when compared to povidone-iodine. ${ }^{36}$ Subsequent investigations have supported the superiority of chlorhexidine in the prevention of CLABSIs. ${ }^{37}$ Chlorhexidine has been demonstrated to affect a greater reduction in skin flora for a longer period of time than povidone-iodine and is not inactivated by blood or serum proteins. ${ }^{38}$ Current guidelines recommend that an alcohol-based chlorhexidine solution with a minimum chlorhexidine gluconate concentration of $0.5 \%$ be applied to the skin surface and allowed to dry prior to catheter insertion. ${ }^{16,18} \mathrm{Chlorhexidine} \mathrm{skin} \mathrm{preparations} \mathrm{are} \mathrm{not}$ approved by the US Food and Drug Administration (FDA) for use in children younger than 2 months of age. In these patients, povidone-iodine should be used instead.

\section{Location of catheter}

Use of the femoral vein for central venous access has been associated with greater rates of CLABSI. A prospective observational study of medical-surgical ward patients in a Veteran Affairs hospital identified an association between catheter colonization and femoral CVC placement (hazard ratio $[\mathrm{HR}] 4.2$; 95\% CI: $2.0-8.8 ; P=0.0001) .{ }^{39} \mathrm{~A}$ multicenter, randomized, controlled trial involving eight ICUs in France later demonstrated an association between femoral catheterization and increased infectious and thrombotic complications when compared to the subclavian approach (HR 4.83; 95\% CI: 1.96-11.93, $P<0.001$ ). ${ }^{4}$ A subsequent prospective observational study, also in critically ill patients, showed that the incidence density of CLABSI was significantly higher for femoral (8.34) than for either jugular (2.99) or subclavian (0.97) approaches. ${ }^{40}$ In a subgroup analysis of femoral catheterizations for short-term dialysis access in critically ill patients, a body mass index $>28.4$ was found to be associated with an even higher risk of infection. ${ }^{41}$ When the option exists, the current evidence supports either a jugular or subclavian approach for CVC placement, with some studies favoring the latter. ${ }^{40,42,43}$ In inpatients, the use of peripherally inserted central venous catheters (PICC) has emerged as an alternative to conventional CVCs in those requiring intermediate- to long-term vascular access, given their lower insertion complication rates. Yet, a prospective cohort study of ICU patients with PICCs yielded CLABSI rates similar to that of internal jugular and subclavian CVCs placed using the conventional approach. ${ }^{44}$ Therefore, the risk of CLABSI is not necessarily attenuated by the use of a PICC in every setting.

\section{Systems-based intervention}

Systems-based interventions promote greater adherence to the best practices described above. Use of a dedicated cart or kit standardizes CVC placement procedures and improves compliance with sterile technique. At one hospital, a routinely used standard CVC kit contained a small sterile drape and $10 \%$ povidone-iodine antiseptic. ${ }^{45}$ This kit was replaced with a customized kit containing a large sterile drape and $2 \%$ chlorhexidine gluconate in $70 \%$ isopropyl alcohol, which correlated with a decrease in CLABSI rates. The use of a universal catheter checklist not only prompts compliance but also ensures proper documentation of the utilization of infection-prevention strategies (Figure 1). A nurse, physician, or other trained health care professional should be appointed to observe the insertion of the CVC, review the checklist, monitor sterile technique, and should be empowered to terminate the procedure if breaches are identified.

Several single-center studies have demonstrated the positive impact on CLABSI rates when comprehensive infection-prevention strategies, integrating education, and evidence-based guidelines are implemented. ${ }^{46,47}$ A collaborative cohort of 103 ICUs across Michigan saw reduction in CLABSI rates by up to $66 \%$ over an 18 -month period after a multifaceted intervention targeted hand hygiene, maximal barrier sterile precautions, chlorhexidine skin preparation, avoidance of the femoral site when possible, and removal of unnecessary catheters. ${ }^{10} \mathrm{~A}$ central line cart was stocked with the necessary supplies, and a checklist was used to document adherence. In nonemergency situations, CVC placement was stopped if sterile technique was breached. ICU teams received regular feedback regarding CLABSI rates. At 3 months after implementation of this quality improvement program, the median rate of CLABSI had decreased from a preintervention baseline of 2.7 to 0 infections/1000 catheter-days $(P \leq 0.002)$. CLABSI rates decreased from 7.7 at baseline to 1.4 between 16 and 18 months of follow-up $(P<0.002)$ with a sustained reduction in CLABSI rates of up to $66 \%$. CLABSI incidence rate ratios decreased from 0.62 (95\% CI: $0.47-0.81)$ at $0-3$ months after initiation of the intervention to 0.34 (95\% CI: $0.23-0.50)$ at 16-18 months of follow-up. These reductions were sustained at 36 months of follow-up beyond the initial intervention. ${ }^{5}$ Similar successes were demonstrated in a cohort of 69 ICUs across southwestern Pennsylvania, where CLABSI rates declined from 4.3 to 
(Patient Label)

NOT a part of the patient's Medical Record.

Return to the Infection Prevention department.

Line placed emergently

Inserter:

Room/Unit:

Date: Observer:

Type of Line \& Site:

Vascular Catheter Insertion Checklist

Each person present is required to identify, stop, correct and report
any break in aseptic technique before resuming the insertion procedure.

Persons within sterile field must wear mask, cap, sterile gown and gloves.

Any person in room/area must, at minimum, wear a mask during line insertion.

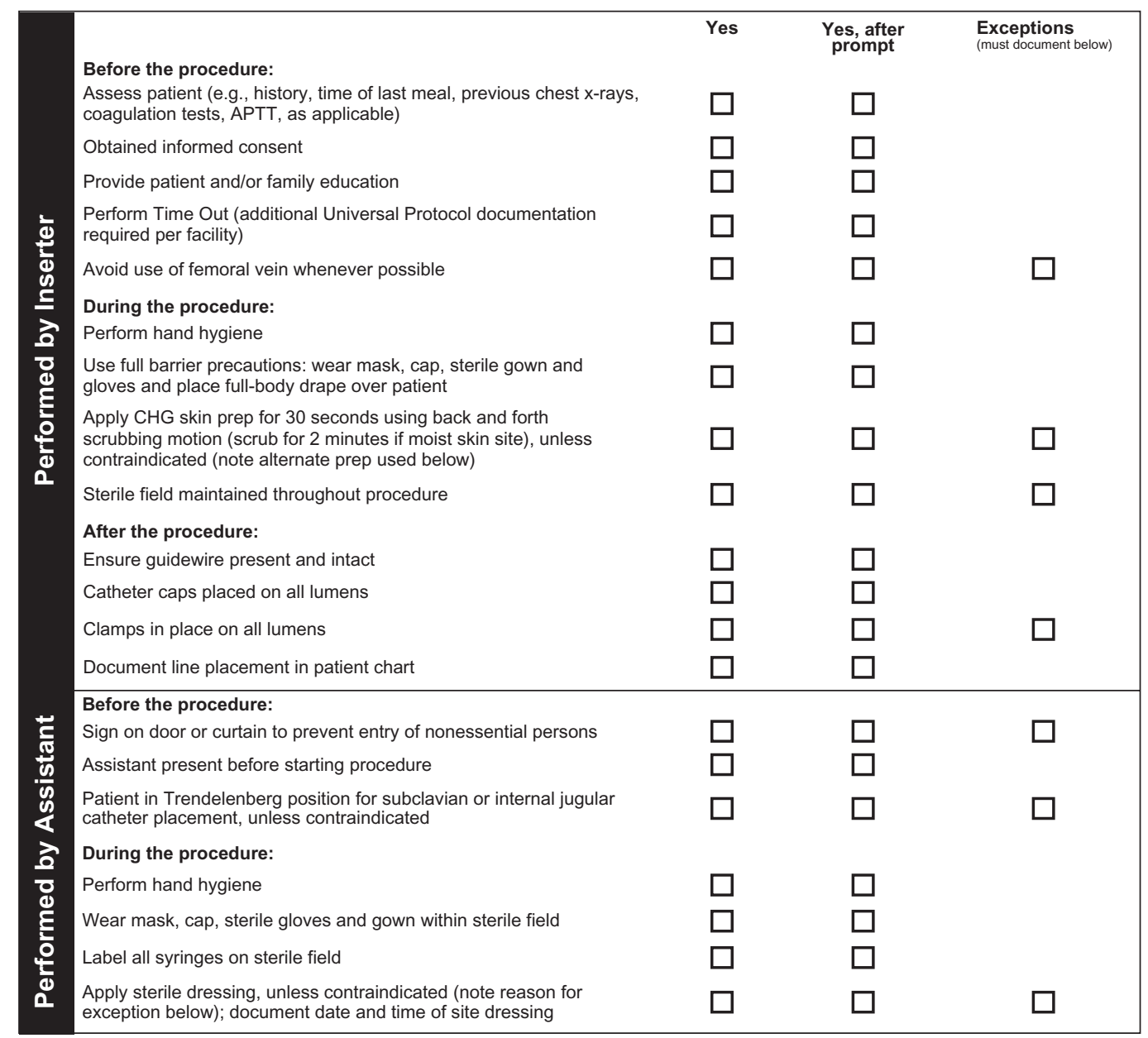

Document exceptions here:

10/05/09

BJC 9-8001-020

BJCHealthCare

Figure I Example of a central vascular catheter insertion checklist. Copyright @ 2010, reproduced with permission from BJC Infection Prevention and Epidemiology Consortium.

1.4 infections/1000 catheter-days over a 4-year period after comparable interventions $(P<0.001) .{ }^{48}$ On the basis of the success of these trials, CLABSI prevention bundles have been developed to promote best practices and improve patient outcomes in diverse hospital settings. ${ }^{49,50}$

\section{After catheter insertion} Catheter care

Chlorhexidine-impregnated sponge dressings have emerged as a means to decrease skin flora colonization at the catheter insertion site and the subsequent risk of infection after 
CVC insertion. A meta-analysis of eight studies examining the impact of chlorhexidine-impregnated sponge dressings on vascular and epidural catheter infection demonstrated a significant reduction in catheter and exit-site colonization with a possible trend toward decreased CLABSI rates. ${ }^{51}$ A large randomized, controlled trial consisting of 3778 catheter episodes was later carried out in seven ICUs in France to further evaluate this question. Use of chlorhexidine-impregnated sponge dressings resulted in lower rates of major catheterrelated infection ( 0.6 versus $1.4 / 1000$ catheter-days; HR 0.39 , 95\% CI: $0.17-0.93 ; P=0.03)$ and CLABSI (0.4 infections versus 1.3/1000 catheter-days; HR 0.24, 95\% CI: 0.09-0.65; $P=0.005$ ) when compared to standard dressings, despite a low-baseline infection rate. ${ }^{52}$ Another randomized, controlled trial of cancer patients undergoing chemotherapy also found a decreased incidence of CLABSIs in patients who received a chlorhexidine-impregnated sponge dressing compared to a standard sterile dressing $(6.3 \%$ versus $11.3 \%$, respectively; RR 0.54, 95\% CI: 0.31-0.94). ${ }^{53}$

Dressing changes for nontunneled CVC should be performed every 5-7 days in the absence of visible soiling or a break in the seal of the dressing. A multicenter, randomized, controlled study involving bone marrow transplant patients with tunneled- and nontunneled catheters demonstrated no significant increase in local infection or colonization when dressing changes occurred at longer intervals. ${ }^{54}$ In a larger randomized, trial, catheter colonization rates were similar between catheters assigned to 3- and 7-day interval dressing changes indicating noninferiority for the latter approach. ${ }^{52}$ Catheter site care with a chlorhexidine solution during dressing changes is advised. Catheter hubs, needleless connectors, and injection ports should be disinfected with either chlorhexidine or $70 \%$ alcohol prior to use to reduce the risk of contamination. ${ }^{55}$ Evidence has emerged demonstrating that some types of needleless connectors may be associated with increased CLABSI rates. ${ }^{56}$ Intravenous administration sets not used to infuse blood products or lipids may remain safely in place for up to 96 hours without an increased incidence of infection. ${ }^{57}$ Administration sets containing blood products and lipids should be changed every 24 hours.

In some cases, antimicrobial locks for patients requiring long-term hemodialysis catheters have been shown to reduce the risk of CLABSIs. ${ }^{58}$ The instillation of antimicrobial solution (eg, gentamicin, cefotaxime, and minocycline) at supraphysiologic concentrations into the catheter lumen between hemodialysis sessions is thought to prevent intraluminal colonization and biofilm formation. However, the potential for antibiotic resistance and systemic toxicity from inadvertent leakage of antimicrobial solution at the catheter tip present important considerations. The use of taurolidine-citrate locks has not been shown to reduce the incidence of bacteremia as expected. ${ }^{59}$ In general, antimicrobial locks should be reserved for special populations with a history of limited venous access, recurrent CLABSI, or who are at increased risk for adverse sequelae from a CLABSI. Antimicrobial lock therapy for treatment of CLABSI will be addressed in greater detail in the section on management of CLABSI.

\section{Reassessing the need for a catheter}

The need for continued central venous access should be reevaluated on a daily basis as part of a multidisciplinary approach to patient care.$^{60} \mathrm{CVCs}$ no longer required for medical care should be promptly discontinued to eliminate the risk of future CLABSI. The incorporation of these infectionprevention practices into CVC maintenance bundles has proven beneficial in decreasing CLABSI rates beyond the time around initial catheter placement. ${ }^{61}$ Finally, an ongoing surveillance program to monitor CLABSI incidence (reported per 1000 catheter-days) should be implemented to facilitate evaluation and validation of preventive strategies.

\section{Special considerations}

\section{Antibiotic-coated catheters}

The use of CVCs impregnated with antiseptics (eg, chlorhexidine/silver sulfadiazine) or antimicrobials (eg, minocycline/rifampin) remains controversial. Such coated catheters are thought to discourage microbial colonization and biofilm formation of the catheter lumen or exterior. A meta-analysis recently examined 38 randomized, controlled trials spanning from 1993 through $2007^{62}$ comparing antiinfective-treated with standard CVCs. Of these, 27 trials provided CLABSI rates and revealed an advantage to use treated CVCs (OR 0.49, 95\% CI: 0.37-0.64). It was unclear whether this advantage would persist after effective infection control bundles developed over the same period became standard of care. A separate meta-analysis showed that minocycline/ rifampin CVCs were associated with greater reductions in colonization and CLABSI compared to first-generation chlorhexidine/silver sulfadiazine $\mathrm{CVCs} .{ }^{63}$ Both meta-analyses commented on the overall poor methodological quality of the existing literature and iterated the need for further research. The use of these catheters is recommended primarily in clinical settings where CLABSI rates remain high despite standard preventive strategies. ${ }^{16}$ Use may also be considered in patients with limited venous access and a history of recur- 
rent CLABSI. Finally, patients with prosthetic devices or biomaterials (eg, heart valve or aortic graft) who are at a higher risk for adverse sequelae (eg, endocarditis) from a CLABSI may also be benefited.

\section{Management of central line-associated bloodstream infections}

In confirmed or suspected CLABSI, management is multifaceted and encompasses the selection of an empiric antibiotic, the determination of whether the infected catheter should be removed, the narrowing of antibiotic spectrum once a pathogen has been isolated, and a number of other considerations.

\section{Empiric treatment for central line-associated bloodstream infections}

Vancomycin is recommended for the empiric treatment of CLABSI as CNS are the most common causative microorganisms, and also because of an increased prevalence of MRSA in many geographic areas. ${ }^{64}$ However, in situations where the minimal inhibitory concentration (MIC) for vancomycin is $\geq 2 \mathrm{ug} / \mathrm{mL}$, alternative agents such as daptomycin should be used. ${ }^{65,66}$ Linezolid should not be used for empiric therapy due to increased mortality reported in recipients with negative blood cultures or Gram-negative bacteremia. ${ }^{67}$

Additional coverage for Gram-negative bacilli should be administered in patients with severe illness, sepsis, a femoral catheter in place, a known focus of Gram-negative bacterial infection, or immunocompromised states including neutropenia or malignancy ${ }^{68,69}$ Empiric coverage for Gram-negative bacilli should be based on local antimicrobial susceptibility data; appropriate choices include a fourth-generation cephalosporin, a carbapenem, or a $\beta$-lactam/ $\beta$-lactamase inhibitor combination, with or without an aminoglycoside. Dual empiric antibiotic coverage for suspected multidrugresistant (MDR) Gram-negative bacilli such as Pseudomonas aeruginosa can be used until susceptibility data are available and antibiotic therapy can be de-escalated. ${ }^{70}$ For critically ill patients with femoral catheters, Candida spp. should be covered in addition to bacterial pathogens. ${ }^{71}$ Empiric coverage for central line-associated candidemia should also be initiated in septic patients with any of the following risk factors: total parenteral nutrition, prolonged use of broad-spectrum antibiotics, hematologic malignancy, bone marrow or solid-organ transplant, or colonization with Candida spp. at multiple sites. ${ }^{1}$ An echinocandin (eg, anidulafungin, micafungin, or caspofungin) is the preferred antifungal agent for treatment of suspected central line-associated candidemia. ${ }^{72}$

The duration of therapy for CLABSI is dependent on the organism suspected or isolated as well as evidence for endovascular sequelae. Treatment of an uncomplicated CLABSI due to Enterococcus or Gram-negative bacilli ranges from 7 to 14 days, while $S$. aureus may require anywhere from 2 to 4 weeks. Longer courses (4-6 weeks) are required in patients with fungemia or bacteremia that persists more than 72 hours after initiating appropriate antibiotics and removing the infected catheter, as well as in patients with infective endocarditis or suppurative thrombophlebitis. ${ }^{1}$ A further discussion of pathogen-specific treatment and duration of therapy follows.

\section{Catheter removal}

Not all patients with vascular catheters in place and a documented BSI have CLABSI. A catheter does not need to be removed if the BSI was due to an unrelated infection, such as urinary tract infection or pneumonia. Diagnostic approaches to CLABSI have been discussed in the introduction of this article and may help discern if a BSI should be managed as CLABSI or not. In the following paragraphs, we discuss whether an infected catheter should be removed after the diagnosis of CLABSI has been made.

Infected short-term catheters such as peripheral venous catheters, peripheral arterial catheters, midline catheters, and short-term, nontunneled CVCs should be removed. ${ }^{73}$

Long-term catheters such as PICCs, long-term tunneled CVCs, and implantable devices should be removed in patients with CLABSI with any of the following conditions: severe sepsis, suppurative thrombophlebitis, endocarditis, metastatic complications such as pulmonary embolism, peripheral embolism in the setting of arterial catheters, BSI that continues $>72$ hours after appropriate antibiotic therapy, infection due to $S$. aureus, fungi, or mycobacteria, or tunnel or pocket infections. ${ }^{1}$ Catheters that are in place for $<2$ weeks are often infected extraluminally and should be removed. Antibiotic lock therapy (discussed in detail below) is unlikely to be effective in the setting of an extraluminal infection ${ }^{74-77}$ and should be reserved for managing long-term catheter infections. Catheters infected by Gram-negative organisms should be removed as retained catheters have been associated with significantly higher rates of treatment failure and recurrence. ${ }^{78}$ However, recent studies have shown high success rates in the treatment of CLABSI caused by Gram-negative organisms combining systemic antibiotic and antibiotic lock therapy in selected patients. ${ }^{75,79}$ 
For low-virulence organisms that are difficult to eradicate including Corynebacterium spp., Bacillus spp., Micrococcus spp., and Propionibacterium, infected catheters should be removed after blood culture contamination is ruled out with multiple positive culture results (see Pathogen-specific treatment for detail). For CNS CLABSI, catheters may be retained and patients may be treated with systemic antibiotic and antibiotic lock therapy. ${ }^{1}$

In uncomplicated CLABSI involving long-term catheters, treatment can be attempted without catheter removal due to limited access sites in patients who require long-term intravascular access for survival. ${ }^{80,81}$ If a catheter is retained, antibiotic lock therapy along with systematic antibiotics is usually recommended for catheter salvage, and repeat blood cultures should be obtained 1 week after antibiotic treatment. ${ }^{82}$ Catheter salvage with systematic antibiotics alone was attempted in selected hemodialysis patients with infected tunneled catheters with an initial success rate of $61 \%$, but recurrence was higher in this group (33\% versus $8 \%) .{ }^{83}$

\section{Antibiotic lock therapy}

Antibiotic concentrations must be 100-1000 times greater to kill sessile bacteria within a biofilm than to kill planktonic bacteria. ${ }^{84}$ Preparing supratherapeutic concentrations of antibiotics and allowing them to dwell intraluminally within an infected catheter for hours to days may facilitate eradication of intraluminal infections because systemic antibiotics cannot achieve therapeutic levels there. Antibiotic lock therapy is a promising approach but is not widely established and should not be used if catheter removal is easily feasible.

Antibiotic lock solutions containing the desired antibiotic solution can be mixed with normal saline or heparin to fill the catheter lumen (typically $2-5 \mathrm{~mL}$ ). In general, lower concentrations of heparin $(\leq 1000$ units $/ \mathrm{mL}$ ) result in antibiotic precipitation, whereas higher concentrations of heparin (3500-10,000 units/mL) are compatible with a wider range of antibiotic concentrations. ${ }^{85}$ The indwelling time for an antibiotic lock should not exceed 48 hours (no more than 24 hours in the case of a femoral catheter) as antibiotic concentrations decrease significantly thereafter. ${ }^{86}$

Commonly used antibiotic lock therapy solutions are listed in Table 1. Other than those listed, teicoplanin, ${ }^{81,87}$ linezolid, ${ }^{85}$ levofloxacin, ${ }^{81}$ cefazolin, ${ }^{76}$ ampicillin, ${ }^{88}$ amoxicillin, ${ }^{89}$ and combined antibiotic lock therapy such as vancomycin + gentamicin ${ }^{76}$ and cefazolin + gentamicin ${ }^{76}$ have been described in the literature.

\section{Managing patients with hemodialysis catheter infection}

Management of hemodialysis catheter infections is challenging not only because the diagnosis is difficult, but also because the catheter is both the source of the infection and at the same time required for providing ongoing dialysis. The diagnosis of catheter infection requires at least one blood culture from a peripheral vein; however, it is not always feasible to draw peripheral blood cultures from patients who are receiving hemodialysis. Peripheral venous access is frequently exhausted from multiple, failed grafts or fistulas. Phlebotomy sites are further limited when future creation of a graft or fistula in an extremity is anticipated. When a peripheral blood culture cannot be obtained, blood samples can be drawn from the dialysis tubing during hemodialysis because systemic blood is circulating extracorporeally. ${ }^{95}$ An infected catheter should be removed immediately in patients with either of the following: severe sepsis, hemodynamic instability, evidence of metastatic infection, signs of accompanying exit-site or tunnel infection, fever and/or bacteremia that persist 72 hours after initiation of antibiotics to which the organism is susceptible, and with infection due to difficult-to-cure pathogens such as S. aureus, Pseudomonas, MDR bacterial pathogens, or Candida and other fungi. ${ }^{96}$ A temporary catheter can be placed at a different anatomical site. A new permanent dialysis catheter can be placed after the BSI has cleared. When there is no alternative site for

Table I Final concentrations of common antibiotic lock solutions

\begin{tabular}{lll}
\hline Antibiotic and dosage & Heparin dosage & References \\
\hline Vancomycin $2 \mathrm{mg} / \mathrm{mL}$ & 10 units $/ \mathrm{mL}$ & Robinson et al $^{88}$ \\
Daptomycin $5 \mathrm{mg} / \mathrm{mL}$ & $100-10,000$ units $/ \mathrm{mL}$ & Carpenter and Chambers $^{90}$ \\
Gentamicin I mg/mL & 2500 units $/ \mathrm{mL}$ & Krishnasami et al $^{76}$ \\
Ciprofloxacin $0.2 \mathrm{mg} / \mathrm{dL}$ & 5000 units $/ \mathrm{mL}$ & Droste et al ${ }^{85}$ \\
Ceftazidime $0.5 \mathrm{mg} / \mathrm{dL}$ & 100 units $/ \mathrm{mL}$ & Rijnders et al $^{91}$ \\
Piperacillin-tazobactam $10 \mathrm{mg} / \mathrm{mL}$ & 100 units $/ \mathrm{mL}$ & Del Pozo et al ${ }^{81}$ \\
Ethanol $70 \%$ & No & Onland et al, ${ }^{92}$ Maiefski et al ${ }^{93}$ \\
& & and Sanders et al ${ }^{94}$ \\
\hline
\end{tabular}

Note: ${ }^{a}$ Heparin partially inhibits the antimicrobial activity of gentamicin, but this inhibition was overcome in vitro by a gentamicin concentration of $\mathrm{I}$ mg/mL. ${ }^{76}$ 
a new catheter, catheter exchange through a guide wire can be attempted, preferably 3 days after appropriate and effective antibiotic treatment. ${ }^{82}$ Hemodialysis catheter infection can be managed with antibiotic lock therapy along with systemic antibiotics for patients without an indication for immediate catheter removal as mentioned above. If a catheter is retained, blood cultures should be checked 1 week after completion of antibiotic treatment. The catheter should be removed if the repeat culture remains positive. ${ }^{82}$ The success rate for catheter salvage varies among infecting organisms, with Gram-negative organisms other than Pseudomonas ranking highest (87\%-100\%), followed by Staphylococcus epidermidis (75\%-84\%), and Enterococcus (61\%). ${ }^{75,76,81}$

Empiric antibiotic therapy for hemodialysis catheter infection should consist of vancomycin for Gram-positive bacteria and a third-generation cephalosporin or an aminoglycoside for Gram-negative coverage. ${ }^{97}$ Third-generation cephalosporins are preferred over aminoglycosides due to the substantial risk of irreversible aminoglycoside oto-/vestibulotoxicity in dialysis patients. ${ }^{98}$ Vancomycinresistant Enterococcus can be treated with daptomycin administered after each dialysis session. Cefazolin is favored over vancomycin in patients with methicillin-sensitive S. aureus (MSSA) bacteremia. ${ }^{99}$ There are higher failure rates in treating MRSA bacteremia if the vancomycin MIC is $\geq 2 \mathrm{ug} / \mathrm{mL} ;{ }^{65}$ daptomycin should be considered in these cases. ${ }^{66}$ Antibiotics that can be dosed after each hemodialysis session are preferable, including vancomycin, ceftazidime, and cefazolin (see Table 2). Candidemia in dialysis patients is treated with echinocandins, amphotericin B, or fluconazole in conjunction with catheter removal. ${ }^{76}$

Hemodialysis patients with uncomplicated CLABSI can be treated with systemic antibiotics for 3 weeks. ${ }^{100}$ Those with metastatic infection such as endocarditis,

Table 2 Preferred antibiotics regimen commonly used in dialysis patients

\begin{tabular}{|c|c|}
\hline Antibiotic & Dosing \\
\hline Vancomycin & $\begin{array}{l}20 \mathrm{mg} / \mathrm{kg} \text { loading dose during the last } \\
\text { hour of the dialysis session, then } \\
500 \mathrm{mg} \text { during the last } 30 \mathrm{~min} \text { of } \\
\text { each subsequent dialysis session }\end{array}$ \\
\hline Gentamicin & $\begin{array}{l}\text { I } \mathrm{mg} / \mathrm{kg} \text {, not to exceed } 100 \mathrm{mg} \text {, after } \\
\text { each dialysis session }\end{array}$ \\
\hline Ceftazidime & I g after each dialysis session \\
\hline Cefazolin & $20 \mathrm{mg} / \mathrm{kg}$ after each dialysis session \\
\hline Daptomycin & $6 \mathrm{mg} / \mathrm{kg}$ after each dialysis session \\
\hline $\begin{array}{l}\text { Echinocandins (caspofungin, } \\
\text { micafungin, and anidulafungin), } \\
\text { fluconazole, or amphotericin B }\end{array}$ & $\begin{array}{l}\text { Dose and frequency are the same as } \\
\text { in nondialysis patients (see Table 3) }\end{array}$ \\
\hline
\end{tabular}

suppurative thrombophlebitis, or persistent bacteremia or fungemia $>72 \mathrm{~h}$ after catheter removal and appropriate antibiotic therapy should receive 4-6 weeks of antibiotics. Patients with secondary osteomyelitis should receive 6-8 weeks of antibiotics. ${ }^{1}$

\section{Pathogen-specific treatment Staphylococcus aureus}

$S$. aureus bacteremia is associated with a high rate of deep-seated metastatic infections. Patients with $S$. aureus CLABSI should undergo prompt catheter removal. Delay in catheter removal increases the risk of hematogenous complications, such as septic arthritis, vertebral osteomyelitis, or endocarditis. ${ }^{74,75}$ Predictors of hematogenous complications include positive blood culture results 72 hours after initiation of appropriate antibiotics or catheter removal, communityacquired infection, hemodialysis dependence, diabetes, and a higher mean APACHE II score. ${ }^{74}$ Transesophageal echocardiogram (TEE) should be performed in patients with persistent fever or BSI $>72 \mathrm{~h}$ after catheter withdrawal in addition to initiation of appropriate antibiotic therapy. ${ }^{1}$ Transthoracic echocardiogram (TTE) findings are insufficient to rule out infective endocarditis. ${ }^{101,102}$

$S$. aureus CLABSI is usually treated for 4-6 weeks. However, a 14-day course of antibiotics may be sufficient if a TEE has ruled out endocarditis for patients without any of the following risk factors for infective endocarditis or other deep tissue infection related to $S$. aureus bacteremia: diabetes, immunosuppression, prosthetic intravascular devices, evidence of endocarditis or suppurative thrombophlebitis on TEE or ultrasound, retained infected catheters, persistent fever, or bacteremia $>72$ hours after appropriate antibiotic treatment. ${ }^{103,104}$

Oxacillin or nafcillin is the drug of choice for MSSA bacteremia, while vancomycin is the standard treatment for MRSA infection. There are higher failure rates in treating MRSA bacteremia if the vancomycin MIC is $\geq 2 \mathrm{ug} / \mathrm{mL} ; 65$ alternative therapy with daptomycin, linezolid, or telavancin should be considered in these cases. ${ }^{66}$ Daptomycin is a cyclic lipopeptide. It causes depolarization of the bacterial cell membrane and is bactericidal. It is approved by the FDA for complicated skin and soft tissue infections and bacteremia with/ without endocarditis due to MRSA or other Gram-positive cocci ${ }^{66,105}$ Linezolid is at least noninferior to vancomycin in patients with CLABSI caused by Gram-positive organisms. ${ }^{66}$ However, prolonged use can cause significant side effects such as bone marrow suppression and peripheral neuropathy. Outbreaks of linezolid-resistant MRSA have been reported. ${ }^{106}$ 
Linezolid, however, should not be used for empiric therapy due to increased mortality reported in recipients with negative culture results or Gram-negative bacteremia as mentioned before. Telavancin inhibits cell wall synthesis by binding to peptidoglycan chain precursors and produces bacterial membrane depolarization. It is bactericidal against Gram-positive cocci, including MRSA, vancomycin-intermittent $S$. aureus (VISA), vancomycin-resistant S. aureus (VRSA), and daptomycin- or linezolid-resistant strains of MRSA. ${ }^{107}$ A pilot study comparing telavancin with standard therapy in patients with $S$. aureus bacteremia has been completed but the results remain forthcoming.

\section{Coagulase-negative Staphylococci species}

CNS are the most common cause of CLABSI. ${ }^{108}$ They are also the most common skin flora associated with blood culture contamination. The best indicator of a true CLABSI due to CNS is a high proportion of positive blood cultures performed on samples drawn from multiple sites including at least one from a peripheral vein. ${ }^{108}$ However, in a septic patient, even a single positive CNS blood culture should be considered clinically relevant. Untreated CNS bacteremia in this situation can lead to significant mortality. ${ }^{109}$ For uncomplicated CLABSI due to CNS, catheters can be salvaged with systemic antibiotic and antibiotic lock therapy for 10-14 days. A shorter duration (5-7 days) of treatment may be acceptable if the infected catheter is removed. ${ }^{1}$

CLABSI due to $S$. lugdunensis can cause endocarditis and metastatic infections similar to those caused by $S$. aureus and should be managed in a manner similar to CLABSI due to S. aureus. ${ }^{110}$ However, S. lugdunensis is frequently susceptible to a wider range of antibiotics than $S$. aureus.

\section{Enterococcus species}

Patients with CLABSI due to ampicillin-sensitive Enterococcus spp. should receive ampicillin as the first-line antibiotic therapy. Vancomycin can be used if the pathogen is resistant to ampicillin. Linezolid or daptomycin is used in vancomycin-resistant Enterococcus spp. The infected catheter should be removed when possible. If the catheter removal is not feasible due to coagulopathy or need for central venous access, antibiotic lock therapy combined with systemic antibiotics can be attempted, and combination therapy with an aminoglycoside is preferred. ${ }^{111}$

\section{Gram-negative bacilli}

Although Gram-positive organisms are the most common cause of CLABSI, Gram-negative organisms have been increasingly associated with BSIs. ${ }^{112}$ Multidrug resistance is a growing concern in Gram-negative bacteria. Enterobacteriaceae such as Escherichia coli and Klebsiella spp. can be extended-spectrum $\beta$-lactamase (ESBL) producers. ESBLproducing organisms confer broad-spectrum resistance to third-generation cephalosporins, $\beta$-lactamase inhibitor combinations, and aztreonam. They may initially appear to be susceptible to these antibiotics and lead to inappropriate antibiotic selection and treatment failure. ${ }^{113}$ Carbapenems are the treatment of choice due to their superior activity against ESBL-producing organisms. ${ }^{114,115}$ However, the incidence of infections with carbapenem-resistant Gram-negative bacteria is increasing, especially for Acinetobacter spp. ${ }^{116}$ Fortunately, sulbactam, polymyxin E (colistin), and aminoglycosides all have activity against Acinetobacter spp. Sulbactam is commercially available only in combination with ampicillin. It is given in a fixed 2:1 ratio of ampicillin/sulbactam $3 \mathrm{~g}$ q6h. Polymyxin E is given $2.5-5 \mathrm{mg} / \mathrm{kg} / \mathrm{day}$, divided by three times a day in patients with normal renal function. ${ }^{117}$ Although tigecycline has activity against Acinetobacter spp., it achieves very low serum concentrations and is not recommended for BSIs.

Controversy exists regarding whether combination therapy is necessary to treat $P$. aeruginosa infections assuming a benefit of synergism. However, a meta-analysis that evaluated 64 randomized, trials comparing $\beta$-lactam monotherapy to a $\beta$-lactam in combination with an aminoglycoside failed to show a survival benefit. ${ }^{118}$ It seems reasonable to use combination therapy while antibiotic susceptibilities are pending in order to increase the likelihood that the organism is covered by at least one of the antibiotics used, especially in the case of suspected MDR P. aeruginosa.

Catheters infected with Gram-negative organisms should be removed because retained catheters have been associated with significantly higher rates of treatment failure and infection recurrence. ${ }^{69,78}$ However, recent studies have shown high success rates in treating CLABSI caused by Gram-negative organisms with systemic antibiotics and antibiotic lock therapy. ${ }^{75,79}$ In the case of Pseudomonas CLABSI, catheter removal is usually required, ${ }^{1,78}$ although treatment with systematic antibiotics in addition to antibiotic lock therapy has also shown success in selected cases. $^{79}$ The duration of treatment should be 7-14 days if the infected catheter is removed, and 10-14 days if the catheter is retained. ${ }^{1}$

\section{Candida species}

Echinocandins are the preferred treatment in central lineassociated candidemia. For patients who cannot tolerate 
echinocandins, liposomal amphotericin B is an alternative. Fluconazole can be considered if patients are not critically ill and if they have not had recent exposure to azoles. An echinocandin is preferred in patients who have had recent azole exposure, whose illness is severe, or who is at high risk of infection with C. glabrata or C. krusei. ${ }^{72}$ C. krusei is intrinsically resistant to fluconazole and has variable sensitivity to voriconazole. C. glabrata is frequently resistant to the azoles. Echinocandins have excellent activity against $C$. glabrata and are the drug of choice. C. parapsilosis is susceptible to most antifungal agents; however, the MIC for C. parapsilosis for all echinocandins is higher than that of other Candida spp., and fluconazole is therefore the preferred antibiotic. Treatment for $\sim 14$ days after the first negative blood culture is sufficient in uncomplicated candidemia without persistent fungemia or metastatic complications. ${ }^{72}$ All patients with candidemia should undergo a dilated ophthalmological evaluation to exclude Candida endophthalmitis after the candidemia is controlled and new spread to the eye is unlikely. Ophthalmological examination in neutropenic patients should be performed after recovery of neutrophil counts because neutropenic patients may not manifest visible signs of endophthalmitis before that. ${ }^{72}$

Infected catheters usually need be removed in CLABSI due to Candida spp. ${ }^{119,120}$ However, not all candidemia episodes are central line-associated. Raad et al evaluated 404 cases of candidemia in patients with cancer and CVCs and found that catheter removal within 72 hours from the first positive blood culture was necessary for patients with central line-associated candidemia, but did not change the outcome when the candidemia was not associated with a central line. ${ }^{121}$ The study found that most cases of candidemia were unlikely to be central line-associated and were either related to disseminated candidiasis or to having received corticosteroids/ chemotherapy within the month before onset of candidemia. ${ }^{121}$ One exception is C. parapsilosis, which is more frequently associated with catheters compared to other Candida spp. ${ }^{122}$ Both echinocandins and liposomal amphotericin B penetrate well into Candida biofilms and exhibit similar MICs in biofilms and in planktonic stage; however, resistance to fluconazole has been described in Candida biofilms even though Candida in planktonic form was fluconazole sensitive. ${ }^{123}$ A recent analysis of 842 patients from two randomized, clinical trials implied that early removal of a CVC within 48 hours of the detection of candidemia was not warranted in adults treated with an echinocandin or liposomal amphotericin B. ${ }^{124}$ However, the authors did not distinguish between CVC-related and -unrelated candidemia in their study.

\section{Other Gram-positive microorganisms}

Diagnosis of CLABSI due to Corynebacterium, Bacillus, and Micrococcus spp. requires at least two positive results of blood cultures performed on samples obtained from different sites. Commonly regarded as contaminants, isolation of these organisms from a single blood culture set does not necessarily indicate a true BSI. ${ }^{1}$ Catheters frequently need to be removed. ${ }^{125-127}$ However, recent experience has shown a high success rate in catheter salvage with appropriate antimicrobial therapy. ${ }^{128,129}$ The empiric antibiotic of choice is vancomycin. Therapy can be adjusted according to in vitro susceptibility for definitive treatment. If catheters are retained in Bacillus CLABSI, alternative antibiotics such as linezolid or carbapenems may be more effective than vancomycin. ${ }^{125}$ Ciprofloxacin is associated with recurrent infection in Micrococcus bacteremia and should be avoided even if in vitro susceptibility studies demonstrate sensitivity to this antibiotic (Table 3 ). ${ }^{127}$

\section{Management of complications of CLABSI: suppurative thrombophlebitis and infective endocarditis}

Suppurative thrombophlebitis and infective endocarditis must be considered in patients with persistent bacteremia or fungemia $>72$ hours of adequate antimicrobial therapy. Catheter removal is mandatory in both circumstances.

Patients with suppurative thrombophlebitis due to CLABSI should receive a minimum of 3-4 weeks of antimicrobial therapy. Whether heparin therapy should be included in the treatment of this condition remains controversial. ${ }^{135}$ Surgical resection of the involved vein/thrombus is only indicated in patients with purulent superficial veins, patients in whom the infection extends beyond the vessel wall, or patients who have failed an antibiotic regimen. ${ }^{136}$

TEE to evaluate the possibility of an endocarditis should be performed in patients with CLABSI who have any of the following: a prosthetic heart valve, a pacemaker, an implantable defibrillator, persistent bacteremia/fungemia $>72$ hours of adequate antimicrobial therapy and catheter removal, or any case of $S$. aureus $C L A B S I$ in which a duration of therapy of $<4-6$ weeks is considered. ${ }^{137-139}$ Current IDSA guidelines for treatment of endocarditis should be consulted. ${ }^{140}$

\section{Conclusion}

CLABSIs are among the most frequent health care-associated infections and cause significant morbidity and mortality as well as increased costs to the health care system. Preventive measures have been shown to lead to significant reduction of 


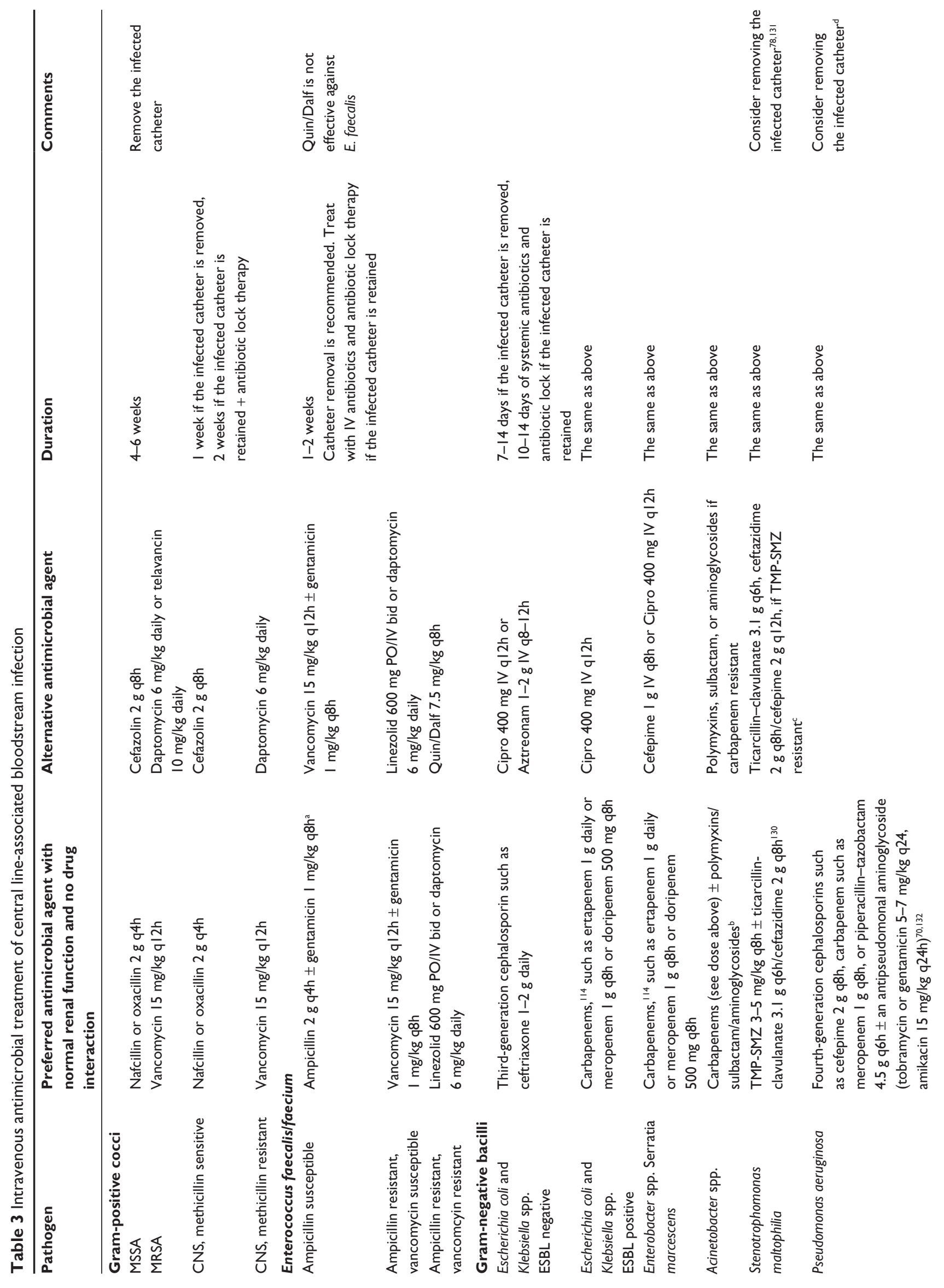




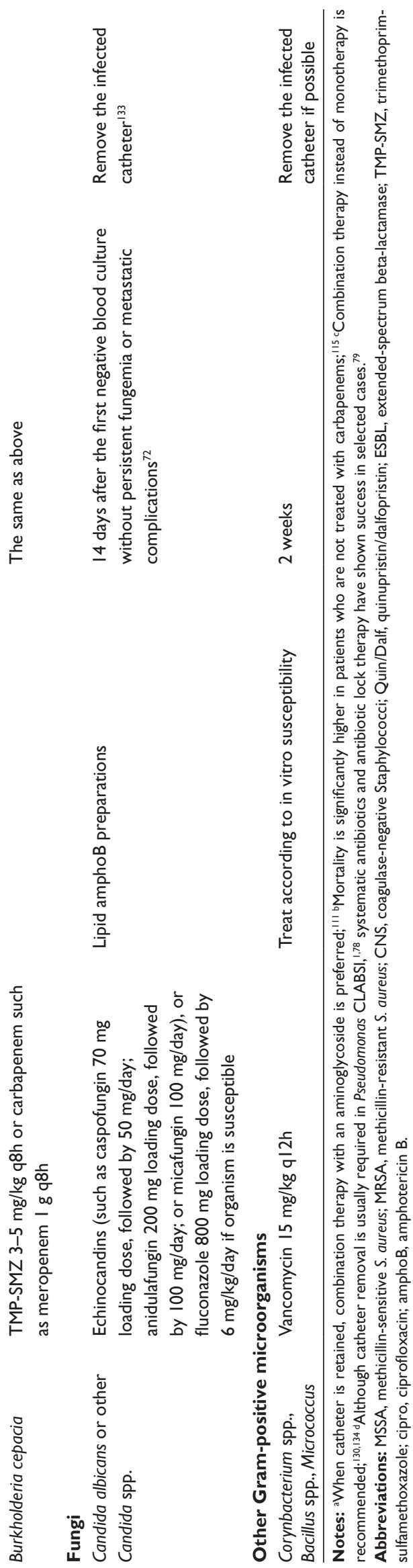

these infections, as exemplified by the bundling of a number of interventions in the landmark study by Pronovost et al. ${ }^{5}$ The field of CLABSI prevention is evolving further, with the most recent development being the roll out of evidence-based strategies to multiple US states. ${ }^{141}$ There are, however, many topics that still deserve closer investigation, eg, what are the optimal precautions at time of catheter insertion, what is the role of maintenance checklists to ensure proper catheter site care, what infection risks are associated with specific needleless connectors, and what is the role of antibiotic lock solutions for prevention. The management of CLABSI, on the other hand, has been standardized by the recently updated, excellent IDSA guideline which gives detailed instructions for commonly encountered pathogens and management problems. ${ }^{1}$ In many cases, catheter removal is considered an essential part of the management; however, the data behind this are not equal in strength for all pathogens. Other topics that deserve further studies are can catheter removal alone without antibiotic treatment be a viable approach (specifically for CNS), what is the optimal time period after CLABSI before reinserting a new catheter, what is the optimal treatment duration in retained catheters, do all S. aureus CLABSIs require an echocardiogram to define the treatment duration, and are follow-up blood cultures necessary after completing treatment. Although more and more evidence for the best practices in prevention and management of CLABSIs is accumulated, many questions remain to be elucidated.

\section{Disclosure}

The authors report no conflicts of interest in this work.

\section{References}

1. Mermel LA, Allon M, Bouza E, et al. Clinical practice guidelines for the diagnosis and management of intravascular catheter-related infection: 2009 update by the Infectious Diseases Society of America. Clin Infect Dis. 2009;49(1):1-45.

2. Kallen AJ, Patel PR, O'Grady NP. Preventing catheter-related bloodstream infections outside the intensive care unit: expanding prevention to new settings. Clin Infect Dis. 2010;51(3):335-341.

3. Maki DG, Kluger DM, Crnich CJ. The risk of bloodstream infection in adults with different intravascular devices: a systematic review of 200 published prospective studies. Mayo Clin Proc. 2006;81(9):1159-1171.

4. Merrer J, de Jonghe B, Golliot F, et al. Complications of femoral and subclavian venous catheterization in critically ill patients: a randomized controlled trial. JAMA. 2001;286(6):700-707.

5. Pronovost PJ, Goeschel CA, Colantuoni E, et al. Sustaining reductions in catheter related bloodstream infections in Michigan intensive care units: observational study. BMJ. 2010;340:c309.

6. Raad I, Hanna H, Maki D. Intravascular catheter-related infections: advances in diagnosis, prevention, and management. Lancet Infect Dis. 2007;7(10):645-657.

7. Woeltje KF, Butler AM, Goris AJ, et al. Automated surveillance for central line-associated bloodstream infection in intensive care units. Infect Control Hosp Epidemiol. 2008;29(9):842-846. 
8. Edgeworth J. Intravascular catheter infections. J Hosp Infect. 2009; 73(4):323-330.

9. Zingg W, Sax H, Inan C, et al. Hospital-wide surveillance of catheterrelated bloodstream infection: from the expected to the unexpected. $J$ Hosp Infect. 2009;73(1):41-46.

10. Pronovost P, Needham D, Berenholtz S, et al. An intervention to decrease catheter-related bloodstream infections in the ICU. $N$ Engl J Med. 2006;355(26):2725-2732.

11. Horan TC, Andrus M, Dudeck MA. CDC/NHSN surveillance definition of health care-associated infection and criteria for specific types of infections in the acute care setting. Am J Infect Control. 2008; 36(5):309-332.

12. Maki DG, Weise CE, Sarafin HW. A semiquantitative culture method for identifying intravenous-catheter-related infection. $N$ Engl J Med. 1977;296(23):1305-1309.

13. Safdar N, Fine JP, Maki DG. Meta-analysis: methods for diagnosing intravascular device-related bloodstream infection. Ann Intern Med. 2005;142(6):451-466.

14. Siegman-Igra Y, Anglim AM, Shapiro DE, Adal KA, Strain BA, Farr BM. Diagnosis of vascular catheter-related bloodstream infection: a meta-analysis. J Clin Microbiol. 1997;35(4):928-936.

15. Blot F, Nitenberg G, Chachaty E, et al. Diagnosis of catheter-related bacteraemia: a prospective comparison of the time to positivity of hub-blood versus peripheral-blood cultures. Lancet. 1999;354(9184): 1071-1077.

16. Marschall J, Mermel LA, Classen D, et al. Strategies to prevent central line-associated bloodstream infections in acute care hospitals. Infect Control Hosp Epidemiol. 2008;29 Suppl 1:S22-S30.

17. Yokoe DS, Mermel LA, Anderson DJ, et al. A compendium of strategies to prevent healthcare-associated infections in acute care hospitals. Infect Control Hosp Epidemiol. 2008;29 Suppl 1:S12-S21.

18. O'Grady NP, Alexander M, Dellinger EP, et al. Guidelines for the prevention of intravascular catheter-related infections. Centers for Disease Control and Prevention. MMWR Recomm Rep. 2002;51(RR-10): 1-29.

19. Safdar N, Abad C. Educational interventions for prevention of healthcare-associated infection: a systematic review. Crit Care Med. 2008;36(3):933-940.

20. Sherertz RJ, Ely EW, Westbrook DM, et al. Education of physiciansin-training can decrease the risk for vascular catheter infection. Ann Intern Med. 2000;132(8):641-648.

21. Warren DK, Zack JE, Mayfield JL, et al. The effect of an education program on the incidence of central venous catheter-associated bloodstream infection in a medical ICU. Chest. 2004;126(5): $1612-1618$.

22. Coopersmith CM, Rebmann TL, Zack JE, et al. Effect of an education program on decreasing catheter-related bloodstream infections in the surgical intensive care unit. Crit Care Med. 2002;30(1):59-64.

23. Warren DK, Zack JE, Cox MJ, Cohen MM, Fraser VJ. An educational intervention to prevent catheter-associated bloodstream infections in a nonteaching, community medical center. Crit Care Med. 2003;31(7): 1959-1963.

24. Warren DK, Cosgrove SE, Diekema DJ, et al. A multicenter intervention to prevent catheter-associated bloodstream infections. Infect Control Hosp Epidemiol. 2006;27(7):662-669.

25. Barsuk JH, Cohen ER, Feinglass J, McGaghie WC, Wayne DB. Use of simulation-based education to reduce catheter-related bloodstream infections. Arch Intern Med. 2009;169(15):1420-1423.

26. Boyce JM, Pittet D. Guideline for hand hygiene in health-care settings: recommendations of the Healthcare Infection Control Practices Advisory Committee and the HICPAC/SHEA/APIC/IDSA Hand Hygiene Task Force. Infect Control Hosp Epidemiol. 2002; 23 Suppl 12:S3-S40.

27. Pittet D, Allegranzi B, Sax H, et al. Evidence-based model for hand transmission during patient care and the role of improved practices. Lancet Infect Dis. 2006;6(10):641-652.

28. Allegranzi B, Pittet D. Role of hand hygiene in healthcare-associated infection prevention. $J$ Hosp Infect. 2009;73(4):305-315.
29. Pittet D, Hugonnet S, Harbarth S, et al. Effectiveness of a hospital-wide programme to improve compliance with hand hygiene. Infection Control Programme. Lancet. 2000;356(9238):1307-1312.

30. Yilmaz G, Koksal I, Aydin K, Caylan R, Sucu N, Aksoy F. Risk factors of catheter-related bloodstream infections in parenteral nutrition catheterization. JPEN J Parenter Enteral Nutr. 2007;31(4):284-287.

31. Rosenthal VD, Guzman S, Safdar N. Reduction in nosocomial infection with improved hand hygiene in intensive care units of a tertiary care hospital in Argentina. Am J Infect Control. 2005;33(7):392-397.

32. Zingg W, Imhof A, Maggiorini M, Stocker R, Keller E, Ruef C. Impact of a prevention strategy targeting hand hygiene and catheter care on the incidence of catheter-related bloodstream infections. Crit Care Med. 2009;37(7):2167-2173; quiz 2180.

33. Raad II, Hohn DC, Gilbreath BJ, et al. Prevention of central venous catheter-related infections by using maximal sterile barrier precautions during insertion. Infect Control Hosp Epidemiol. 1994;15(4 Pt 1): 231-238.

34. Ishikawa $Y$, Kiyama T, Haga $Y$, et al. Maximal sterile barrier precautions do not reduce catheter-related bloodstream infections in general surgery units: a multi-institutional randomized controlled trial. Ann Surg. 2010;251(4):620-623.

35. Maki DG, Ringer M, Alvarado CJ. Prospective randomised trial of povidone-iodine, alcohol, and chlorhexidine for prevention of infection associated with central venous and arterial catheters. Lancet. 1991;338(8763):339-343.

36. Chaiyakunapruk N, Veenstra DL, Lipsky BA, Saint S. Chlorhexidine compared with povidone-iodine solution for vascular catheter-site care: a meta-analysis. Ann Intern Med. 2002;136(11):792-801.

37. Mimoz O, Villeminey S, Ragot S, et al. Chlorhexidine-based antiseptic solution vs alcohol-based povidone-iodine for central venous catheter care. Arch Intern Med. 2007;167(19):2066-2072.

38. Milstone AM, Passaretti CL, Perl TM. Chlorhexidine: expanding the armamentarium for infection control and prevention. Clin Infect Dis. 2008;46(2):274-281.

39. Goetz AM, Wagener MM, Miller JM, Muder RR. Risk of infection due to central venous catheters: effect of site of placement and catheter type. Infect Control Hosp Epidemiol. 1998;19(11):842-845.

40. Lorente L, Henry C, Martin MM, Jimenez A, Mora ML. Central venous catheter-related infection in a prospective and observational study of 2,595 catheters. Crit Care. 2005;9(6):R631-R635.

41. Parienti JJ, Thirion M, Megarbane B, et al. Femoral vs jugular venous catheterization and risk of nosocomial events in adults requiring acute renal replacement therapy: a randomized controlled trial. JAMA. 2008; 299(20):2413-2422.

42. Ruesch S, Walder B, Tramer MR. Complications of central venous catheters: internal jugular versus subclavian access - a systematic review. Crit Care Med. 2002;30(2):454-460.

43. Nagashima G, Kikuchi T, Tsuyuzaki H, et al. To reduce catheter-related bloodstream infections: is the subclavian route better than the jugular route for central venous catheterization? J Infect Chemother. 2006; 12(6):363-365.

44. Safdar N, Maki DG. Risk of catheter-related bloodstream infection with peripherally inserted central venous catheters used in hospitalized patients. Chest. 2005;128(2):489-495.

45. Young EM, Commiskey ML, Wilson SJ. Translating evidence into practice to prevent central venous catheter-associated bloodstream infections: a systems-based intervention. Am J Infect Control. 2006;34(8):503-506.

46. Eggimann P, Harbarth S, Constantin MN, Touveneau S, Chevrolet JC, Pittet D. Impact of a prevention strategy targeted at vascular-access care on incidence of infections acquired in intensive care. Lancet. 2000;355(9218):1864-1868.

47. Berenholtz SM, Pronovost PJ, Lipsett PA, et al. Eliminating catheterrelated bloodstream infections in the intensive care unit. Crit Care Med. 2004;32(10):2014-2020.

48. Reduction in central line-associated bloodstream infections among patients in intensive care units-Pennsylvania, Apr 2001-Mar 2005. MMWR Morb Mortal Wkly Rep. 2005;54(40):1013-1016. 
49. Galpern D, Guerrero A, Tu A, Fahoum B, Wise L. Effectiveness of a central line bundle campaign on line-associated infections in the intensive care unit. Surgery. 2008;144(4):492-495; discussion 495.

50. Miller RS, Norris PR, Jenkins JM, et al. Systems initiatives reduce healthcare-associated infections: a study of 22,928 device days in a single trauma unit. J Trauma. 2010;68(1):23-31.

51. Ho KM, Litton E. Use of chlorhexidine-impregnated dressing to prevent vascular and epidural catheter colonization and infection: a meta-analysis. J Antimicrob Chemother. 2006;58(2):281-287.

52. Timsit JF, Schwebel C, Bouadma L, et al. Chlorhexidine-impregnated sponges and less frequent dressing changes for prevention of catheterrelated infections in critically ill adults: a randomized controlled trial. JAMA. 2009;301(12):1231-1241.

53. Ruschulte H, Franke M, Gastmeier P, et al. Prevention of central venous catheter related infections with chlorhexidine gluconate impregnated wound dressings: a randomized controlled trial. Ann Hematol. 2009;88(3):267-272.

54. Laura R, Degl'Innocenti M, Mocali M, et al. Comparison of two different time interval protocols for central venous catheter dressing in bone marrow transplant patients: results of a randomized, multicenter study. The Italian Nurse Bone Marrow Transplant Group (GITMO). Haematologica. 2000;85(3):275-279.

55. Salzman MB, Isenberg HD, Rubin LG. Use of disinfectants to reduce microbial contamination of hubs of vascular catheters. J Clin Microbiol. 1993;31(3):475-479.

56. Jarvis WR, Murphy C, Hall KK, et al. Health care-associated bloodstream infections associated with negative- or positive-pressure or displacement mechanical valve needleless connectors. Clin Infect Dis. 2009;49(12):1821-1827.

57. Gillies D, O’Riordan L, Wallen M, Morrison A, Rankin K, Nagy S Optimal timing for intravenous administration set replacement. Cochrane Database Syst Rev. 2005(4):CD003588

58. Labriola L, Crott R, Jadoul M. Preventing haemodialysis catheterrelated bacteraemia with an antimicrobial lock solution: a metaanalysis of prospective randomized trials. Nephrol Dial Transplant. 2008;23(5):1666-1672.

59. Solomon LR, Cheesbrough JS, Ebah L, et al. A randomized double-blind controlled trial of taurolidine-citrate catheter locks for the prevention of bacteremia in patients treated with hemodialysis. Am J Kidney Dis. 2010;55(6):1060-1068.

60. Parenti CM, Lederle FA, Impola CL, Peterson LR. Reduction of unnecessary intravenous catheter use. Internal medicine house staff participate in a successful quality improvement project. Arch Intern Med. 1994;154(16):1829-1832.

61. Miller MR, Griswold M, Harris JM 2nd, et al. Decreasing PICU catheterassociated bloodstream infections: NACHRI's quality transformation efforts. Pediatrics. 2010;125(2):206-213.

62. Hockenhull JC, Dwan KM, Smith GW, et al. The clinical effectiveness of central venous catheters treated with anti-infective agents in preventing catheter-related bloodstream infections: a systematic review. Crit Care Med. 2009;37(2):702-712.

63. Casey AL, Mermel LA, Nightingale P, Elliott TS. Antimicrobial central venous catheters in adults: a systematic review and meta-analysis Lancet Infect Dis. 2008;8(12):763-776.

64. National Nosocomial Infections Surveillance (NNIS) system report, data summary from Jan 1992 through Jun 2004, issued Oct 2004. Am J Infect Control. 2004;32(8):470-485.

65. Moise PA, Sakoulas G, Forrest A, Schentag JJ. Vancomycin in vitro bactericidal activity and its relationship to efficacy in clearance of methicillin-resistant Staphylococcus aureus bacteremia. Antimicrob Agents Chemother. 2007;51(7):2582-2586.

66. Fowler VG Jr, Boucher HW, Corey GR, et al. Daptomycin versus standard therapy for bacteremia and endocarditis caused by Staphylococcus aureus. N Engl J Med. 2006;355(7):653-665.

67. Wilcox MH, Tack KJ, Bouza E, et al. Complicated skin and skin-structure infections and catheter-related bloodstream infections: noninferiority of linezolid in a phase 3 study. Clin Infect Dis. 2009;48(2): 203-212.
68. Chee L, Brown M, Sasadeusz J, MacGregor L, Grigg AP. Gram-negative organisms predominate in Hickman line-related infections in nonneutropenic patients with hematological malignancies. $J$ Infect. 2008; 56(4):227-233.

69. Hanna H, Afif C, Alakech B, et al. Central venous catheter-related bacteremia due to Gram-negative bacilli: significance of catheter removal in preventing relapse. Infect Control Hosp Epidemiol. 2004;25(8):646-649.

70. Martinez JA, Cobos-Trigueros N, Soriano A, et al. Influence of empiric therapy with a \{beta -lactam alone or combined with an aminoglycoside on prognosis of bacteremia due to Gram-negative microorganisms. Antimicrob Agents Chemother. 2010;54(9):3590-3596.

71. Lorente L, Jimenez A, Santana M, et al. Microorganisms responsible for intravascular catheter-related bloodstream infection according to the catheter site. Crit Care Med. 2007;35(10):2424-2427.

72. Pappas PG, Kauffman CA, Andes D, et al. Clinical practice guidelines for the management of candidiasis: 2009 update by the Infectious Diseases Society of America. Clin Infect Dis. 2009;48(5):503-535.

73. Benjamin DK Jr, Miller W, Garges H, et al. Bacteremia, central catheters, and neonates: when to pull the line. Pediatrics. 2001;107(6): 1272-1276.

74. Fowler VG Jr, Justice A, Moore C, et al. Risk factors for hematogenous complications of intravascular catheter-associated Staphylococcus aureus bacteremia. Clin Infect Dis. 2005;40(5):695-703.

75. Poole CV, Carlton D, Bimbo L, Allon M. Treatment of catheter-related bacteraemia with an antibiotic lock protocol: effect of bacterial pathogen. Nephrol Dial Transplant. 2004;19(5):1237-1244.

76. Krishnasami Z, Carlton D, Bimbo L, et al. Management of hemodialysis catheter-related bacteremia with an adjunctive antibiotic lock solution. Kidney Int. 2002;61(3):1136-1142.

77. Raad I, Costerton W, Sabharwal U, Sacilowski M, Anaissie E, Bodey GP. Ultrastructural analysis of indwelling vascular catheters: a quantitative relationship between luminal colonization and duration of placement. J Infect Dis. 1993;168(2):400-407.

78. Elting LS, Bodey GP. Septicemia due to Xanthomonas species and non-aeruginosa Pseudomonas species: increasing incidence of catheterrelated infections. Medicine (Baltimore). 1990;69(5):296-306.

79. Fernandez-Hidalgo N, Almirante B, Calleja R, et al. Antibiotic-lock therapy for long-term intravascular catheter-related bacteraemia: results of an open, non-comparative study. J Antimicrob Chemother 2006;57(6):1172-1180.

80. Fortun J, Grill F, Martin-Davila P, et al. Treatment of long-term intravascular catheter-related bacteraemia with antibiotic-lock therapy. J Antimicrob Chemother. 2006;58(4):816-821.

81. Del Pozo JL, Alonso M, Serrera A, Hernaez S, Aguinaga A, Leiva J. Effectiveness of the antibiotic lock therapy for the treatment of portrelated enterococci, Gram-negative, or Gram-positive bacilli bloodstream infections. Diagn Microbiol Infect Dis. 2009;63(2):208-212.

82. Vanholder R, Canaud B, Fluck R, et al. Catheter-related blood stream infections (CRBSI): a European view. Nephrol Dial Transplant. 2010;25(6):1753-1756.

83. Ashby DR, Power A, Singh S, et al. Bacteremia associated with tunneled hemodialysis catheters: outcome after attempted salvage. Clin $J$ Am Soc Nephrol. 2009;4(10):1601-1605.

84. Del Pozo JL. Role of antibiotic lock therapy for the treatment of catheter-related bloodstream infections. Int J Artif Organs. 2009;32(9): 678-688.

85. Droste JC, Jeraj HA, MacDonald A, Farrington K. Stability and in vitro efficacy of antibiotic-heparin lock solutions potentially useful for treatment of central venous catheter-related sepsis. J Antimicrob Chemother. 2003;51(4):849-855.

86. Soriano A, Bregada E, Marques JM, et al. Decreasing gradient of antibiotic concentration in the lumen of catheters locked with vancomycin. Eur J Clin Microbiol Infect Dis. 2007;26(9):659-661.

87. Del Pozo JL, Garcia Cenoz M, Hernaez S, et al. Effectiveness of teicoplanin versus vancomycin lock therapy in the treatment of port-related coagulase-negative Staphylococci bacteraemia: a prospective case-series analysis. Int J Antimicrob Agents. 2009;34(5):482-485. 
88. Robinson JL, Tawfik G, Saxinger L, Stang L, Etches W, Lee B. Stability of heparin and physical compatibility of heparin/antibiotic solutions in concentrations appropriate for antibiotic lock therapy. J Antimicrob Chemother. 2005;56(5):951-953.

89. Boorgu R, Dubrow AJ, Levin NW, et al. Adjunctive antibiotic/anticoagulant lock therapy in the treatment of bacteremia associated with the use of a subcutaneously implanted hemodialysis access device. ASAIO J. 2000;46(6):767-770.

90. Carpenter CF, Chambers HF. Daptomycin: another novel agent for treating infections due to drug-resistant Gram-positive pathogens. Clin Infect Dis. 2004;38(7):994-1000.

91. Rijnders BJ, van Wijngaerden E, Vandecasteele SJ, Stas M, Peetermans WE. Treatment of long-term intravascular catheterrelated bacteraemia with antibiotic lock: randomized, placebocontrolled trial. J Antimicrob Chemother. 2005;55(1):90-94.

92. Onland W, Shin CE, Fustar S, Rushing T, Wong WY. Ethanol-lock technique for persistent bacteremia of long-term intravascular devices in pediatric patients. Arch Pediatr Adolesc Med. 2006;160(10): 1049-1053.

93. Maiefski M, Rupp ME, Hermsen ED. Ethanol lock technique: review of the literature. Infect Control Hosp Epidemiol. 2009;30(11): 1096-1108.

94. Sanders J, Pithie A, Ganly P, et al. A prospective double-blind randomized trial comparing intraluminal ethanol with heparinized saline for the prevention of catheter-associated bloodstream infection in immunosuppressed haematology patients. J Antimicrob Chemother. 2008;62(4):809-815.

95. Allon M, Daugirdas J, Depner TA, Greene T, Ornt D, Schwab SJ. Effect of change in vascular access on patient mortality in hemodialysis patients. Am J Kidney Dis. 2006;47(3):469-477.

96. Rijnders BJ, Peetermans WE, Verwaest C, Wilmer A, van Wijngaerden E. Watchful waiting versus immediate catheter removal in ICU patients with suspected catheter-related infection: a randomized trial. Intensive Care Med. 2004;30(6):1073-1080.

97. Allon M. Dialysis catheter-related bacteremia: treatment and prophylaxis. Am J Kidney Dis. 2004;44(5):779-791.

98. Feldman L, Efrati S, Eviatar E, et al. Gentamicin-induced ototoxicity in hemodialysis patients is ameliorated by $\mathrm{N}$-acetylcysteine. Kidney Int. 2007;72(3):359-363

99. Stryjewski ME, Szczech LA, Benjamin DK Jr, et al. Use of vancomycin or first-generation cephalosporins for the treatment of hemodialysisdependent patients with methicillin-susceptible Staphylococcus aureus bacteremia. Clin Infect Dis. 2007;44(2):190-196.

100. Allon M. Treatment guidelines for dialysis catheter-related bacteremia: an update. Am J Kidney Dis. 2009;54(1):13-17.

101. Sochowski RA, Chan KL. Implication of negative results on a monoplane transesophageal echocardiographic study in patients with suspected infective endocarditis. J Am Coll Cardiol. 1993;21(1): 216-221.

102. Shapiro SM, Young E, de Guzman S, et al. Transesophageal echocardiography in diagnosis of infective endocarditis. Chest. 1994;105(2): 377-382.

103. Malanoski GJ, Samore MH, Pefanis A, Karchmer AW. Staphylococcus aureus catheter-associated bacteremia. Minimal effective therapy and unusual infectious complications associated with arterial sheath catheters. Arch Intern Med. 1995;155(11):1161-1166.

104. Rosen AB, Fowler VG Jr, Corey GR, et al. Cost-effectiveness of transesophageal echocardiography to determine the duration of therapy for intravascular catheter-associated Staphylococcus aureus bacteremia. Ann Intern Med. 1999;130(10):810-820.

105. Arbeit RD, Maki D, Tally FP, Campanaro E, Eisenstein BI; Daptomycin 98-01 and 99-01 Investigators. The safety and efficacy of daptomycin for the treatment of complicated skin and skin-structure infections. Clin Infect Dis. 2004;38(12):1673-1681.

106. Sanchez Garcia M, de la Torre MA, Morales G, et al. Clinical outbreak of linezolid-resistant Staphylococcus aureus in an intensive care unit. JAMA. 2010;303(22):2260-2264.
107. Higgins DL, Chang R, Debabov DV, et al. Telavancin, a multifunctional lipoglycopeptide, disrupts both cell wall synthesis and cell membrane integrity in methicillin-resistant Staphylococcus aureus. Antimicrob Agents Chemother. 2005;49(3):1127-1134.

108. Wisplinghoff H, Bischoff T, Tallent SM, Seifert H, Wenzel RP, Edmond MB. Nosocomial bloodstream infections in US hospitals: analysis of 24,179 cases from a prospective nationwide surveillance study. Clin Infect Dis. 2004;39(3):309-317.

109. Favre B, Hugonnet S, Correa L, Sax H, Rohner P, Pittet D. Nosocomial bacteremia: clinical significance of a single blood culture positive for coagulase-negative Staphylococci. Infect Control Hosp Epidemiol. 2005;26(8):697-702.

110. Zinkernagel AS, Zinkernagel MS, Elzi MV, et al. Significance of Staphylococcus lugdunensis bacteremia: report of 28 cases and review of the literature. Infection. 2008;36(4):314-321.

111. Sandoe JA, Witherden IR, Au-Yeung HK, Kite P, Kerr KG, Wilcox MH. Enterococcal intravascular catheter-related bloodstream infection: management and outcome of 61 consecutive cases. $J$ Antimicrob Chemother. 2002;50(4):577-582.

112. Albrecht SJ, Fishman NO, Kitchen J, et al. Reemergence of Gram-negative health care-associated bloodstream infections. Arch Intern Med. 2006;166(12):1289-1294.

113. Karas JA, Pillay DG, Muckart D, Sturm AW. Treatment failure due to extended spectrum beta-lactamase. J Antimicrob Chemother. 1996; 37(1):203-204.

114. Goossens H, Grabein B. Prevalence and antimicrobial susceptibility data for extended-spectrum beta-lactamase- and AmpC-producing Enterobacteriaceae from the MYSTIC Program in Europe and the United States (1997-2004). Diagn Microbiol Infect Dis. 2005;53(4): 257-264.

115. Paterson DL, Ko WC, Von Gottberg A, et al. Antibiotic therapy for Klebsiella pneumoniae bacteremia: implications of production of extended-spectrum beta-lactamases. Clin Infect Dis. 2004;39(1): 31-37.

116. Brown S, Amyes S. OXA (beta)-lactamases in Acinetobacter: the story so far. J Antimicrob Chemother. 2006;57(1):1-3.

117. Michalopoulos A, Falagas ME. Treatment of Acinetobacter infections. Expert Opin Pharmacother. 2010;11(5):779-788.

118. Paul M, Benuri-Silbiger I, Soares-Weiser K, Leibovici L. Beta lactam monotherapy versus beta lactam-aminoglycoside combination therapy for sepsis in immunocompetent patients: systematic review and meta-analysis of randomised trials. BMJ. 2004; 328(7441):668.

119. Nguyen MH, Peacock JE Jr, Tanner DC, et al. Therapeutic approaches in patients with candidemia. Evaluation in a multicenter, prospective, observational study. Arch Intern Med. 1995;155(22): 2429-2435.

120. Nucci M, Colombo AL, Silveira F, et al. Risk factors for death in patients with candidemia. Infect Control Hosp Epidemiol. 1998;19(11): 846-850.

121. Raad I, Hanna H, Boktour M, et al. Management of central venous catheters in patients with cancer and candidemia. Clin Infect Dis. 2004;38(8):1119-1127.

122. Anaissie EJ, Rex JH, Uzun O, Vartivarian S. Predictors of adverse outcome in cancer patients with candidemia. Am JMed. 1998;104(3): 238-245

123. Kuhn DM, George T, Chandra J, Mukherjee PK, Ghannoum MA. Antifungal susceptibility of Candida biofilms: unique efficacy of amphotericin B lipid formulations and echinocandins. Antimicrob Agents Chemother. 2002;46(6):1773-1780.

124. Nucci M, Anaissie E, Betts RF, et al. Early removal of central venous catheter in patients with candidemia does not improve outcome: analysis of 842 patients from 2 randomized clinical trials. Clin Infect Dis. 2010;51(3):295-303.

125. Kassar R, Hachem R, Jiang Y, Chaftari AM, Raad I. Management of Bacillus bacteremia: the need for catheter removal. Medicine (Baltimore). 2009;88(5):279-283. 
126. Cotton DJ, Gill VJ, Marshall DJ, Gress J, Thaler M, Pizzo PA. Clinical features and therapeutic interventions in 17 cases of Bacillus bacteremia in an immunosuppressed patient population. J Clin Microbiol. 1987;25(4):672-674.

127. Ramos ER, Hachem R, Youssef S, Fang X, Jiang Y, Raad I. The crucial role of catheters in micrococcal bloodstream infections in cancer patients. Infect Control Hosp Epidemiol. 2009;30(1): 83-85.

128. Wang CC, Mattson D, Wald A. Corynebacterium jeikeium bacteremia in bone marrow transplant patients with Hickman catheters. Bone Marrow Transplant. 2001;27(4):445-449.

129. Ghide S, Jiang Y, Hachem R, Chaftari AM, Raad I. Catheter-related Corynebacterium bacteremia: should the catheter be removed and vancomycin administered? Eur J Clin Microbiol Infect Dis. 2010;29(2): $153-156$.

130. Muder RR, Harris AP, Muller S, et al. Bacteremia due to Stenotrophomonas (Xanthomonas) maltophilia: a prospective, multicenter study of 91 episodes. Clin Infect Dis. 1996;22(3):508-512.

131. Friedman ND, Korman TM, Fairley CK, Franklin JC, Spelman DW. Bacteraemia due to Stenotrophomonas maltophilia: an analysis of 45 episodes. J Infect. 2002;45(1):47-53.

132. Mesaros N, Nordmann P, Plesiat P, et al. Pseudomonas aeruginosa: resistance and therapeutic options at the turn of the new millennium. Clin Microbiol Infect. 2007;13(6):560-578.

133. Krzywda EA, Andris DA, Edmiston CE Jr, Quebbeman EJ. Treatment of Hickman catheter sepsis using antibiotic lock technique. Infect Control Hosp Epidemiol. 1995;16(10):596-598.

134. Vartivarian S, Anaissie E, Bodey G, Sprigg H, Rolston K. A changing pattern of susceptibility of Xanthomonas maltophilia to antimicrobial agents: implications for therapy. Antimicrob Agents Chemother. 1994;38(3):624-627.
135. Falagas ME, Vardakas KZ, Athanasiou S. Intravenous heparin in combination with antibiotics for the treatment of deep vein septic thrombophlebitis: a systematic review. Eur J Pharmacol. 2007;557(2-3): 93-98.

136. Kniemeyer HW, Grabitz K, Buhl R, Wust HJ, Sandmann W. Surgical treatment of septic deep venous thrombosis. Surgery. 1995;118(1):49-53.

137. Pigrau C, Rodriguez D, Planes AM, et al. Management of catheterrelated Staphylococcus aureus bacteremia: when may sonographic study be unnecessary? Eur J Clin Microbiol Infect Dis. 2003;22(12): 713-719.

138. Chrissoheris MP, Libertin C, Ali RG, Ghantous A, Bekui A, Donohue T Endocarditis complicating central venous catheter bloodstream infections: a unique form of health care associated endocarditis. Clin Cardiol. 2009;32(12):E48-E54.

139. Fernandez-Guerrero ML, Herrero L, Bellver M, Gadea I, Roblas RF, de Gorgolas M. Nosocomial enterococcal endocarditis: a serious hazard for hospitalized patients with enterococcal bacteraemia. $J$ Intern Med. 2002;252(6):510-515.

140. Baddour LM, Wilson WR, Bayer AS, et al. Infective endocarditis: diagnosis, antimicrobial therapy, and management of complications: a statement for healthcare professionals from the Committee on Rheumatic Fever, Endocarditis, and Kawasaki Disease, Council on Cardiovascular Disease in the Young, and the Councils on Clinical Cardiology, Stroke, and Cardiovascular Surgery and Anesthesia, American Heart Association: endorsed by the Infectious Diseases Society of America. Circulation. 2005;111(23):e394-e434.

141. Sawyer M, Weeks K, Goeschel CA, et al. Using evidence, rigorous measurement, and collaboration to eliminate central catheterassociated bloodstream infections. Crit Care Med. 2010;38 Suppl 8 S292-S298.
Infection and Drug Resistance

\section{Publish your work in this journal}

Infection and Drug Resistance is an international, peer-reviewed openaccess journal that focuses on the optimal treatment of infection (bacterial, fungal and viral) and the development and institution of preventive strategies to minimize the development and spread of resistance. The journal is specifically concerned with the epidemiology of antibiotic

\section{Dovepress}

resistance and the mechanisms of resistance development and diffusion in both hospitals and the community. The manuscript management system is completely online and includes a very quick and fair peerreview system, which is all easy to use. Visit http://www.dovepress.com/ testimonials.php to read real quotes from published authors. 